\title{
Identification of a Homozygous PEX26 Mutation in a Heimler Syndrome Patient
}

\author{
Youn Jung Kim ${ }^{1,+}$, Yuichi Abe ${ }^{2,+}$, Young-Jae Kim ${ }^{3}$, Yukio Fujiki ${ }^{2,4, *}$ and Jung-Wook Kim ${ }^{1,3, *(D)}$ \\ 1 Department of Molecular Genetics, School of Dentistry \& DRI, Seoul National University, Seoul 03080, Korea; \\ ykim71@snu.ac.kr \\ 2 Faculty of Arts and Science, Kyushu University, Fukuoka 819-0315, Japan; abe.yuichi.439@m.kyushu-u.ac.jp \\ 3 Department of Pediatric Dentistry, School of Dentistry \& DRI, Seoul National University, Seoul 03080, Korea; \\ neokarma@snu.ac.kr \\ 4 Institute of Rheological Functions of Food, Fukuoka 811-2501, Japan \\ * Correspondence: yfujiki@kyudai.jp (Y.F.); pedoman@snu.ac.kr (J.-W.K.) \\ + These authors equally contributed to this work.
}

Citation: Kim, Y.J.; Abe, Y.; Kim, Y.-J.; Fujiki, Y.; Kim, J.-W. Identification of a Homozygous PEX26 Mutation in a Heimler Syndrome Patient. Genes 2021, 12, 646. https://doi.org/ $10.3390 /$ genes 12050646

Academic Editor: Laura Crisponi

Received: 7 April 2021

Accepted: 26 April 2021

Published: 26 April 2021

Publisher's Note: MDPI stays neutral with regard to jurisdictional claims in published maps and institutional affiliations.

Copyright: (c) 2021 by the authors. Licensee MDPI, Basel, Switzerland. This article is an open access article distributed under the terms and conditions of the Creative Commons Attribution (CC BY) license (https:/ / creativecommons.org/licenses/by/ $4.0 /)$.

\begin{abstract}
This study aimed to identify the molecular genetic etiology of an 8-year-old boy with amelogenesis imperfecta in permanent dentition. Bilateral cochlear implants were placed due to sensorineural hearing loss, and there was no other family member with a similar phenotype. Peripheral blood samples were collected with the understanding and written consent of the participating family members. A constitutional chromosome study was performed for the proband. Genomic DNA was isolated, and whole exome sequencing was performed. A series of bioinformatic analyses were performed with the obtained paired-end sequencing reads, and the variants were filtered and annotated with dbSNP147. There was no abnormality in the constitutional chromosome study. Whole exome sequencing analysis with trio samples identified a homozygous mutation (c.506T >C,

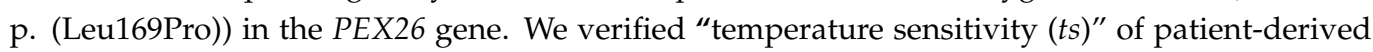
Pex26-L169P by expression in pex26 CHO mutant ZP167 cells to determine the effect of the L169P mutation on Pex26 function. The L169P mutation causes a mild ts-cellular phenotype representing the decreased peroxisomal import of catalase. This study supports the finding that the recessive mutations in PEX26 are associated with Heimler syndrome and demonstrates the importance of an early and correct diagnosis.
\end{abstract}

Keywords: amelogenesis imperfecta; hearing loss; whole exome sequencing; PEX26; temperature sensitivity; Heimler syndrome

\section{Introduction}

Amelogenesis imperfecta (AI) is a collection of hereditary enamel defects that are heterogeneous in genetic etiology and clinical phenotype [1]. Clinically, AI can be categorized as hypoplastic, hypocalcification and hypomaturation according to the characteristics of the affected enamel. In some cases, it is hard to determine the exact clinical phenotype; therefore, the hypocalcification and hypomaturation types are grouped as the hypomineralization type [2].

AI can occur as an isolated entity without non-oral symptoms or as an accompanied phenotype to a syndrome [3]. Heimler syndrome (HS, OMIM \#234580 for HMLR1 and \#616617 for HMLR2) is a rare autosomal recessive disorder characterized by sensorineural hearing loss, AI, nail abnormalities, and occasional or late-onset retinal pigmentation [4,5]. It has been identified that hypomorphic mutations in the peroxisome-biogenesis genes PEX1 (OMIM *602136) and PEX6 (OMIM *601498) cause HS [6]. Recent findings suggest that HS is caused by mutations in PEX26 (OMIM *608666) as well [7].

In this study, we recruited a nuclear family with sensorineural hearing loss and AI in the permanent dentition and identified a homozygous mutation in the PEX26 gene. Early 
molecular diagnostics as a precision medicine confirmed HS in the proband and enabled us to refer the proband to the appropriate medical personnel and manage the symptoms.

\section{Materials and Methods}

\subsection{Human Subjects Enrollment}

The study protocol was reviewed and approved by the Institutional Review Board at Seoul National University Dental Hospital. A nuclear Korean family was recruited for this genetic study. Clinical and radiological examinations were performed, and peripheral blood samples were collected with the understanding and written consent of each participant or a guardian according to the Declaration of Helsinki.

\subsection{DNA Isolation and Whole Exome Sequencing}

A constitutional chromosome study was performed for the proband. Genomic DNA was isolated from $2 \mathrm{~mL}$ of peripheral whole blood from the participating family members with the NucleoSpin genomic DNA purification kit (Macherey-Nagel GmbH \& Co., Düren, Germany), and the quality and quantity of the purified DNA were measured. Whole exome sequencing was performed after exome capturing with the Agilent SureSelect XT Human All Exon V5 Target Enrichment System, and 101-bp paired-end sequencing reads were obtained with the Illumina HiSeq 2500 (Theragen Etex Bio Institute, Suwon-si, Korea).

\subsection{Bioinformatic Analysis}

The program Cutadapt was used to trim the adapter sequences from the obtained sequencing reads [8], and the trimmed sequence reads were aligned to the human reference genome assembly hg38 with the Burrows-Wheeler Aligner [9]. A series of bioinformatics tools [10-12], including Samtools, Genome Analysis Tool Kit, and Annovar, were used to obtain sequence variants including nucleotide changes and small insertions and deletions. Sequence variants were annotated with dbSNP build 147 and filtered with a cutoff value of 0.01 for the minor allele frequency (MAF). FishingCNV was used to detect copy number variation $(\mathrm{CNV})$ in exome sequencing data [13].

\subsection{Sanger Sequencing}

Sanger sequencing was performed to confirm the identified variation in the PEX26 gene (chr22(GRCh38): NG_008339.1:g.10652T>C; NC_000022.11:g.18083571T>C; NM_01792 9.5:c.506T>C; NP_060399.1:p.(Leu169Pro); NCBI Gene ID:55670). PCR amplifications (491 bp) were done with the HiPi DNA polymerase premix (Elpis Biotech, Daejeon, Korea) using exon 4 specific primers (forward primer: 5'-GAGGGGCTGGATAGGAGAAG-3'; reverse primer: $5^{\prime}$-TGCTTCTAAGCTCGCAGGAG-3'). PCR amplification products were purified with a PCR purification kit following the manufacturer's instructions (Elpis Biotech). DNA sequencing was performed with the reverse primer at a DNA sequencing center (Macrogen, Seoul, Korea).

\subsection{Cell Culture}

PEX26-deficient CHO cell mutant ZP167 [14] was maintained in Ham's F-12 medium (Invitrogen) supplemented with $10 \%$ FBS under conditions of $5 \% \mathrm{CO}_{2}, 95 \%$ air at $37^{\circ} \mathrm{C}$. For analysis of temperature-sensitive ( $t s$ ) phenotype, cells were cultured at $42{ }^{\circ} \mathrm{C}$ for 2 days.

\subsection{Transfection of PEX26}

pex26 ZP167 cells were transfected with the expression plasmids each containing pCMVSPORT-FLAG-PEX26 and -FLAG-PEX26-L169P by lipofection [14].

\subsection{Antibodies \& Other Methods}

Rabbit anti-catalase antiserum [15] and guinea pig anti-Pex14 antiserum [16] were used for cell staining. Mouse monoclonal antibody to the FLAG epitope (M2; Sigma) was 
purchased. Rabbit anti-Pex14 antibody [17] was used in immunoblotting. Immunoblotting and immunofluorescence microscopy were performed as described [18].

\section{Results}

The proband was an 8-year-old boy from a non-consanguineous family presenting with enamel hypoplasia in the permanent dentition with severe tooth sensitivity to thermal stimuli (Figure 1A). The primary dentition was reported to be normal without any symptoms. The primary second molars were treated with stainless steel crowns due to dental caries. His permanent first molars showed brown discoloration, and the enamel was very thin (Figure 1B-D). The permanent anterior teeth also showed brown discoloration and hypoplastic AI. Interestingly, the maxillary central incisors had a unique form of hypoplastic and discolored enamel. The buccal side of the teeth showed relatively normal looking areas in the middle and cervical thirds. A panoramic radiograph revealed hypoplastic enamel in the developing permanent dentition (Figure 1E).

He was born 4 weeks premature, but his weight was normal. One week after birth, he was kept in an incubator for two weeks due to a high fever. He was allergic to milk products until the age of 1 year; thus, he had been fed soy milk. His hearing was normal at birth, but gradually worsened, and he was diagnosed with progressive sensorineural hearing loss at the age of 1 year 6 months. The cochlear implant surgery was done at age 6 and 7 years, separately (Figure 1F). He has been wearing Dream Lenses at night because recently, his vision has been rapidly deteriorating bilaterally. Otherwise, there are no other symptoms, and there are no other family members with a similar phenotype (Figure 1G,H).

There was no abnormality in the constitutional chromosome study. Whole exome sequencing resulted in good mapping rates and target coverages (Table 1). CNV analysis with FishingCNV gave no candidate. PEX1 and PEX6 were further checked manually with IGV browser.

Table 1. Statistics for whole exome sequencing.

\begin{tabular}{|c|c|c|c|c|c|c|}
\hline \multirow{2}{*}{ Sample } & \multirow{2}{*}{ Total Reads } & \multirow{2}{*}{$\begin{array}{l}\text { Mapping Rate } \\
(\%)\end{array}$} & \multirow{2}{*}{$\begin{array}{l}\text { Median Target } \\
\text { Coverage }\end{array}$} & \multirow{2}{*}{$\begin{array}{l}\text { Coverage of Target } \\
\text { Region (\%) }\end{array}$} & \multicolumn{2}{|c|}{$\begin{array}{c}\text { Fraction of Target Covered with } \\
\text { at Least }\end{array}$} \\
\hline & & & & & $20 X$ & $10 X$ \\
\hline $\mathrm{I}: 1$ & $69,365,294$ & 99.6 & 95 & 96.5 & 93.5 & 95.5 \\
\hline $\mathrm{I}: 2$ & $68,921,817$ & 99.6 & 87 & 96.3 & 93 & 95.3 \\
\hline II:1 & $59,890,807$ & 99.7 & 82 & 96.5 & 92.8 & 95.4 \\
\hline
\end{tabular}

Annotated exonic and splicing variants from whole exome trio analysis were further filtered. Variants with benign prediction by Polyphen-2 were filtered. Filtered variants were selected according to the genotypes. There was no spontaneous variant. Therefore, homozygous and compound heterozygous variants were selected (Table 2).

Table 2. Filtered sequence variants.

\begin{tabular}{|c|c|c|c|c|c|}
\hline Genomic Variant & Gene & Amino Acid Change & dbSNP & Genotype & CADD \\
\hline chr1:146972960A $>\mathrm{G}$ & NBPF12 & NM_001278141:p.(Lys601Glu) & & homozygous & 9.37 \\
\hline chr1:146994509C>G & NBPF12 & NM_001278141:p.(Ser1436Arg) & rs202167770 & homozygous & 0.088 \\
\hline chr13:146994509insGCCGCC & $D A C H 1$ & NM_004392:p.(Gly81_Ser82insAlaAla) & . & homozygous & \\
\hline chr19:56088071insTCG & ZNF787 & NM_001002836:p.(Asp366dup) & & homozygous & \\
\hline chr22:18083571T $>C$ & PEX26 & NM_017929:p.(Leu169Pro) & rs768604587 & homozygous & 25.9 \\
\hline chr9:66986614C $>\mathrm{T}$ & SPATA31A3 & NM_001083124:p.(Arg1295Gln) & rs759025747 & Heterozygous & 10.16 \\
\hline chr9:66987043G $>\mathrm{T}$ & SPATA31A3 & NM_001083124:p.(Pro1152Gln) & rs11261518 & Heterozygous & 11.94 \\
\hline $\operatorname{chr} 9: 66990002 \mathrm{C}>\mathrm{G}$ & SPATA31A3 & NM_001083124:p.(Ala166Pro) & rs201863232 & Heterozygous & 16.12 \\
\hline
\end{tabular}


A

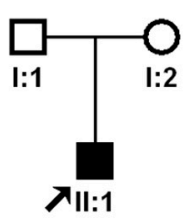

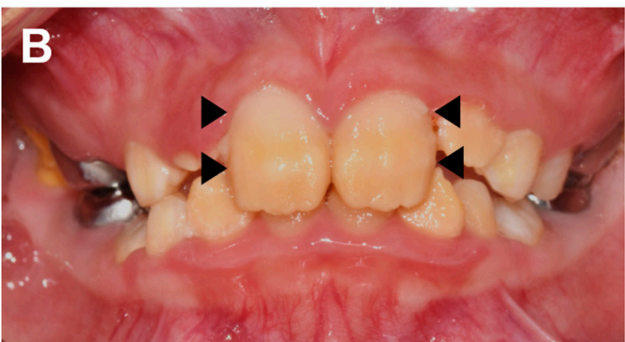
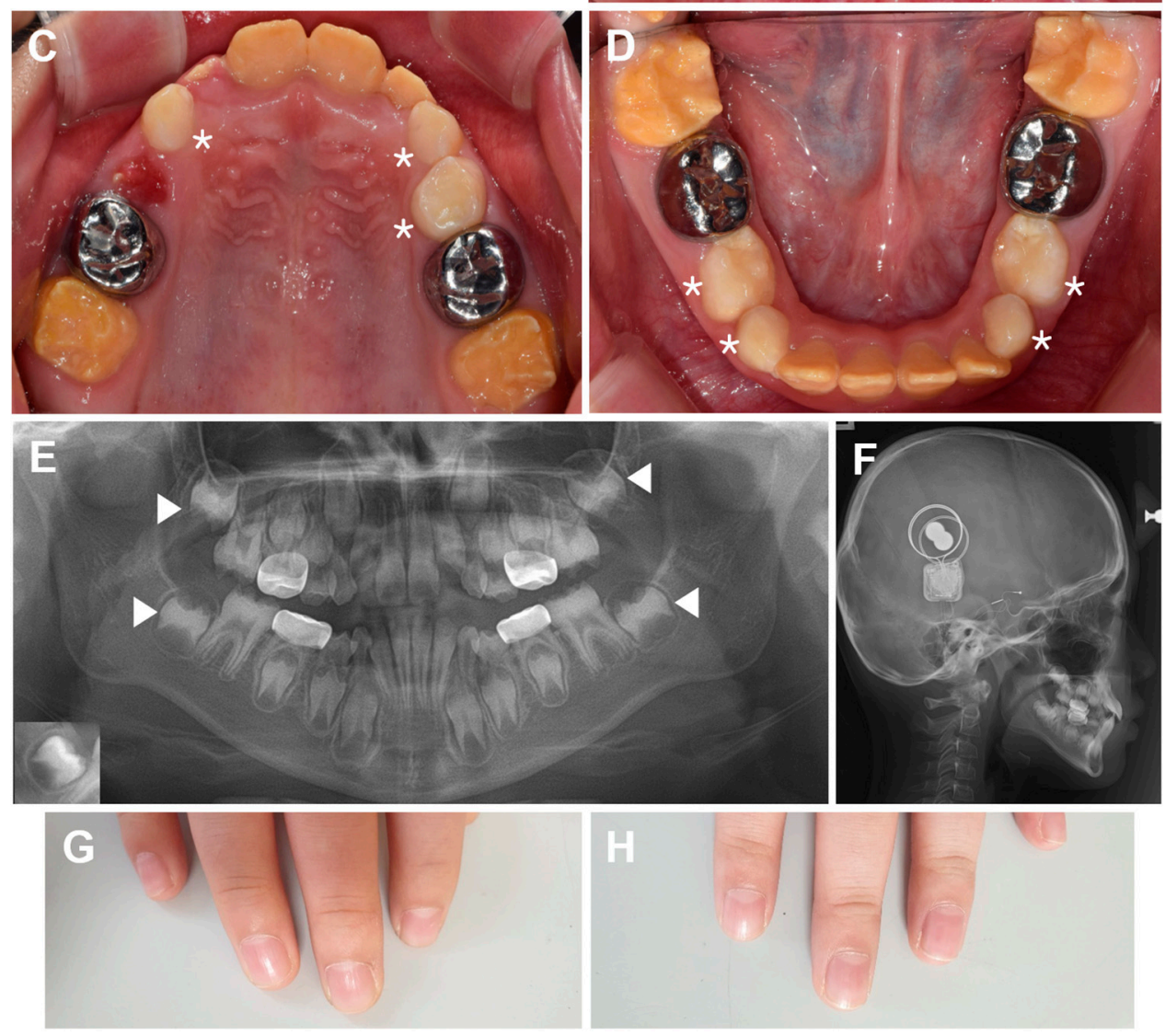

Figure 1. Pedigree, clinical photos, and radiographs of the proband. (A) Pedigree of the family. The arrow indicates the proband, and individual IDs are shown below the symbols. (B-D) Frontal, maxillary and mandibular clinical photos of the proband at age 8 years 7 months. The buccal side of the maxillary central incisors shows relatively normal looking areas in the middle and cervical thirds (black arrow heads). Deciduous teeth (white asterisks) do not have hypoplastic enamel or discoloration, but the permanent teeth show hypoplastic enamel and brown discoloration. (E) A panoramic radiograph revealed hypoplastic enamel in the developing permanent dentition. Almost no covering enamel can be easily seen in the second molars (white arrow heads) compared to the normal tooth in an inset at the lower left corner. (F) Bilateral cochlear implants can be seen in the lateral cephalogram. $(\mathbf{G}, \mathbf{H})$ His finger nails are normal.

Selected sequence variants were further analyzed by a mutation analysis software, Alamut Visual. Variant chr1:146972960A > G was identified in the dbSNP (rs1484197674) with MAF more than 0.1. Likewise, a paternal variant chr9:66986614C $>\mathrm{T}$ was also removed (rs759025747). Another missense variant (chr1:146994509C >G) had prediction being tolerated by SIFT and a low CADD prediction value. Investigation of the two insertional variants (in DACH1 and ZNF787) showed weak conservation with a stretch of the same amino acids near the variant positions. Therefore, the only remaining mutation with a high CADD prediction value was a homozygous mutation in the PEX26 gene. The mother and father were carriers with no related symptoms. The identified mutation 
(NM_017929.6:c.506T>C) would change the leucine to proline at the 169 codon position (Figure 2A). This mutation is listed in dbSNP (rs768604587) with an extremely low allele frequency (2/251186, GnomAD_exome) and is predicted to be deleterious (with a score of 0.00 ), disease-causing (probability of 1 ) or probably_damaging (with a score of 1.000) by in silico analyses (SIFT, Mutation Taster and Polyphen-2, respectively). Moreover, homology analysis showed perfect conservation of the affected amino acid among vertebrates (Figure 2B). Gene diagram of the PEX26 gene is shown with mutations (Figure 2C).

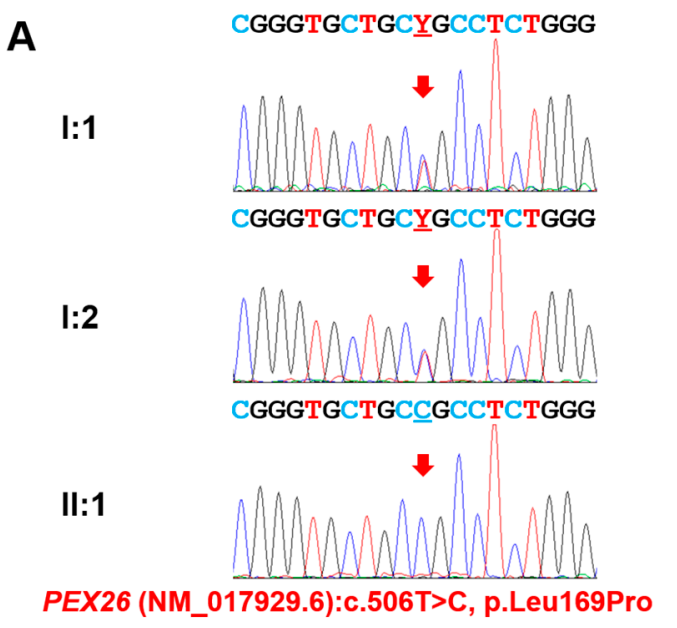

$\begin{array}{ll}\text { B } & \\ \text { Human (NP_060399.1) } & \text { EFHVQRVLLPLGCLSEA } \\ \text { Chimpanzee(XP_024208620.1) } & \text { EFHVQRVLLPLGCLSEA } \\ \text { Monkey (NP_001247589.1) } & \text { EFHVRVLLPLGCLSEA } \\ \text { Dog (XP_022266580.1) } & \text { ELHLQRVLLPLGYLSEA } \\ \text { Catt Ie (NP_001094642.1) } & \text { ELHLQRVLLPLGLLSEA } \\ \text { Mouse (NP_083006. 1) } & \text { RLHVFRLLPSGRLSEA } \\ \text { Rat (NP_001100088.1) } & \text { KLHLFRLLLPLGRLSEA } \\ \text { Chicken(XP_015141777.1) } & \text { ELYLLHVLLPLGRFEGA } \\ \text { Frog(NP_001165772.1) } & \text { ELHLLHILLPLGLFSDA } \\ & ::::: * * * *: *\end{array}$

C

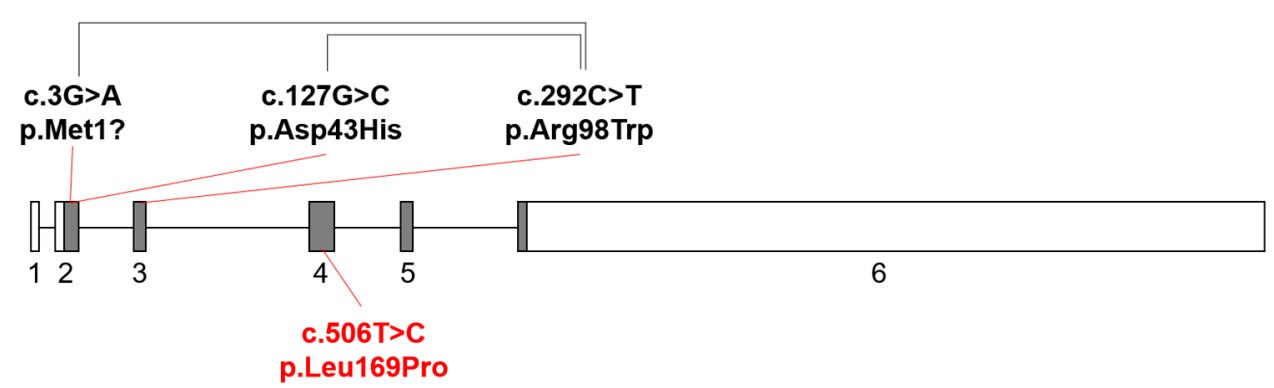

Figure 2. Sequencing chromatograms, homology, and gene diagram. (A) Sequencing chromatograms of the family members. Individual IDs are indicated on the left of each chromatogram. Nucleotide sequences are shown above the chromatograms. The mutated nucleotide is indicated by a red arrow and underlined. Y denotes mixed nucleotides of T and C. (B) Homology among vertebrates. Mutated amino acid is indicated by the bold and red character. Asterisks under the sequences indicate perfectly conserved amino acid positions. (C) Gene diagram of the PEX26 gene (NM_017929.6). Boxes indicate the exons, and the exon numbers are shown below the boxes. Gray areas in the box indicate coding regions, and white areas indicate untranslated regions. Mutations above the diagram are previously reported compound heterozygous mutations, and paired mutations are connected with black connecting lines. The homozygous mutation identified in this study is shown below the diagram.

The functional study revealed the ts phenotype and decreased peroxisomal catalase import by the mutation. In FLAG-Pex26- and endogenous Pex14-expressing pex $26 \mathrm{CHO}$ mutant ZP167 cells, catalase was observed as punctate-staining structures in a manner of colocalization with FLAG-Pex26 and Pex 14 at $37^{\circ} \mathrm{C}$, indicative of localization in the peroxisomes (Figure 3A, a-d, arrowheads). In FLAG-Pex26-L169P- and Pex14-expressing ZP167 cells, catalase was discernible detected observed as punctate-staining, Pex14- and FLAG-Pex26-L169P-positive structures at $37^{\circ} \mathrm{C}$, suggesting that peroxisomal import of catalase was restored, but less efficiently as compared to the FLAG-Pex26 (Figure 3A, i-l, arrowheads; Figure 3B). On the other hand, in Pex26-L169P-expressing and Pex14-positive ZP167 cells ( 10\%), catalase was not detected in puncta, indicative of no import (Figure 3A, $\mathrm{m}-\mathrm{p}$, arrows). ts peroxisome assembly was reported to be responsible for the milder clinical phenotype of infantile Refsum disease (IRD) $[19,20]$. To assess the ts phenotypic property 
of Pex26-L169P, cells were cultured at $42{ }^{\circ} \mathrm{C}$ for 2 days. Catalase was detected mostly in a diffuse staining pattern with FLAG-Pex26-L169P- and Pex14-positive puncta at $42{ }^{\circ} \mathrm{C}$ (Figure $3 \mathrm{~A}, \mathrm{q}-\mathrm{x}$, arrows), indicating that catalase was not imported to peroxisomes at $42^{\circ} \mathrm{C}$ (Figure 3A,B). Expression of normal FLAG-Pex26 in pex 26 ZP167 cells restored the impaired catalase import, efficiently at $37^{\circ} \mathrm{C}$ and $42{ }^{\circ} \mathrm{C}$ (Figure $3 \mathrm{~A}, \mathrm{~B}$ ). These findings suggest the significantly abrogated import of catalase in Pex26-L169P-expressing cells at $42{ }^{\circ} \mathrm{C}$, although catalase was imported at several-fold higher level under normal culture condition at $37^{\circ} \mathrm{C}$. Expressed levels of FLAG-tagged wild-type Pex26 and Pex26-L169P in ZP167 cells were verified by immunoblotting. FLAG-Pex26-L169P was at a level lower than FLAG-Pex26 at both temperatures, suggesting that Pex26-L169P was less stable than the wild-type (Figure 3C). A point of note, is the fact that the expression of FLAG-Pex26 variants was higher at $42{ }^{\circ} \mathrm{C}$, where catalase import was more severely affected in FLAGPex26-L169P-expressing in ZP167 cells, implying the inactivated restoring activity.

A

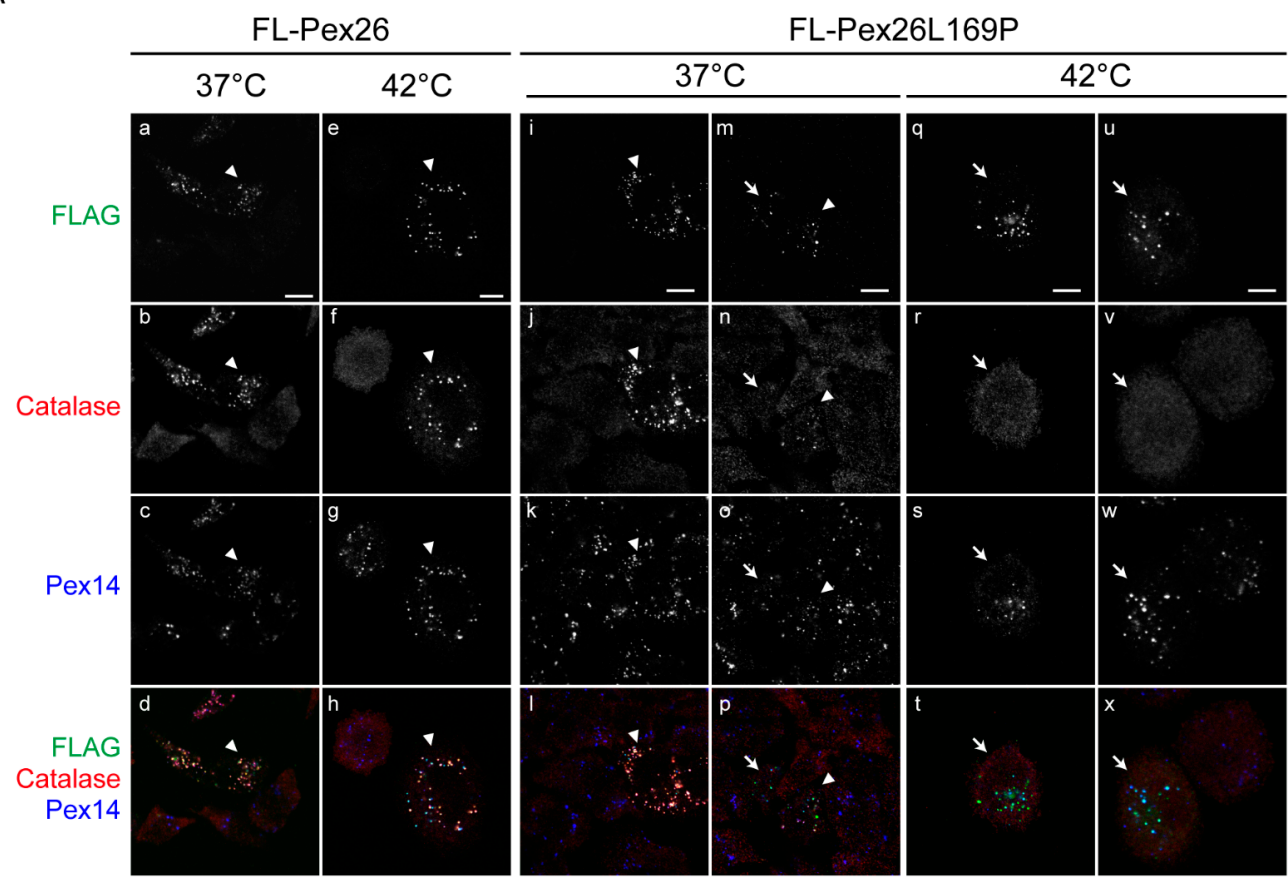

B

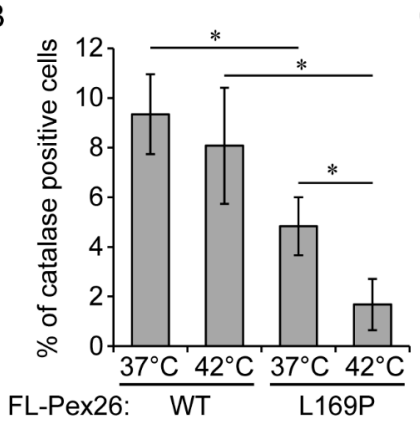

C


Figure 3. Dysfunction of Pex26-L169P. (A) pex26 CHO ZP167 cells transfected with FLAG-tagged human PEX26 and PEX26-L169P were cultured at $37{ }^{\circ} \mathrm{C}$ and $42^{\circ} \mathrm{C}$ for 2 days and then stained with antibodies to FLAG (top panels: a, e, i, $\mathrm{m}, \mathrm{q}$, and $\mathrm{u}$ ), a matrix protein catalase (middle upper panels: $\mathrm{b}, \mathrm{f}, \mathrm{j}, \mathrm{n}, \mathrm{r}$, and $\mathrm{v}$ ), and a membrane peroxin Pex14 (middle lower panels: c, g, k, o, s, and w). Merged views were also shown (bottom panels: $\mathrm{d}, \mathrm{h}, \mathrm{l}, \mathrm{p}, \mathrm{t}$, and $\mathrm{x}$ ). Scale bars, $10 \mu \mathrm{m}$. Arrowheads indicate FLAG-, catalase-, and Pex14-positive cells, whereas arrows show cells positive with FLAG and Pex14. (B) In A, catalase- and FLAG-positive cells were counted and represented as percentages of total cells counted (500 cells each, $n=3$ ). Data represent means \pm S.D. $(n=3) .{ }^{*} p<0.05$; Tukey-Kramer test. (C) Expression level of FLAG-Pex26 and FLAG-Pex26-L169P was analyzed by SDS-PAGE of respective cell lysates and immunoblotting with anti-FLAG antibody (left). Pex14, a loading control. The amounts of both FLAG-Pex26 variants were represented by normalizing the levels of FLAG-Pex26 variants with Pex14 in respective cell lysates (right). 


\section{Discussion}

Peroxisome biogenesis disorders (PBDs) are caused by a failure of peroxisome development, including its membranes, matrix, and assembly. Pathogenic mutations in at least 13 different PEX genes encoding peroxins are responsible for a group of PBDs and Zellweger spectrum disorders (ZSDs) [21]. ZSDs have an estimated prevalence of 1:50,000 births and consist of a spectrum of disorders from a severe to mild form: Zellweger syndrome (ZS, OMIM \#214100), neonatal adrenoleukodystrophy (NALD, OMIM \#601539), infantile Refsum disease (OMIM \#601539), and HS [22].

PEX26, peroxisome biogenesis factor 26, recruits PEX1-PEX6 complexes to peroxisomes, and this complex is involved in the regulation of pexophagy, the autophagic degradation of peroxisomes [23]. The mutation identified in this study would result in a change of a highly conserved amino acid (Leu169) in the PEX6-binding domain (aa29-174) of the PEX26 protein [24].

We analyzed patient-derived Pex26-L169P by expression in pex26 ZP167 cells followed by immunocytochemistry and the "temperature sensitivity" assay to determine the effect of the L169P mutation on Pex26 protein function. Earlier studies on patient-derived fibroblasts have demonstrated the association between Pex26 mutations found in patients with a clinically milder phenotype and the ts cellular phenotype that results from these mutations $[19,20,25]$. In general, fibroblasts from patients with mild ZSD have a ts phenotype, whereas fibroblasts with Pex26 mutations causing the severe ZS clinical phenotype are not ts [19].

We thus characterized the effect of the L169P mutation on Pex26 function by incubating pex 26 ZP167 cells ectopically transfected with FLAG-PEX26-L169P at $37^{\circ} \mathrm{C}$ and $42{ }^{\circ} \mathrm{C}$. At $37^{\circ} \mathrm{C}$, peroxisomal import of catalase appeared less efficient than the import in wildtype Pex26-expressing ZP167 cells (Figure 3A,B). Moreover, at $42^{\circ} \mathrm{C}$, FLAG-Pex26-L169Pexpressing cells severely decreased catalase import as compared to those expressing wildtype FLAG-Pex26 (Figure 3A,B), indicating destabilization of Pex26 activity despite its proper membrane targeting. Interestingly, the total amount of FLAG-Pex26-L169P protein was reduced to $\sim 70 \%$ and $\sim 30 \%$ at $37{ }^{\circ} \mathrm{C}$ and $42{ }^{\circ} \mathrm{C}$, respectively, compared to wild-type FLAG-Pex26 (Figure 3C). This indicates that the mutated protein Pex26-L169P in cells is less stable. Our results collectively show the L169P mutation causes a mild cellular phenotype representing the decreased peroxisomal protein import, implicative to the clinical phenotype of the patient with Heimler syndrome described in this report. Similar ts-phenotype in the catalase import was reported in fibroblasts from patients with Heimler syndrome caused by hypomorphic mutations in PEX1 and PEX6 [6].

HS is a rare and mild form of the ZSDs and mostly caused by mutations in the PEX1 or PEX6 genes [26]. Variant analysis has suggested that HS results from genotypes including milder hypomorphic alleles. HS caused by pathologic mutations in the PEX26 gene is very rare; only one study with two patients has been reported so far [7]. Analysis of the reported HS patients confirmed that the key diagnostic feature of HS from other ZSDs is the existence of the enamel phenotype, AI [26]. It has been noted that the nail abnormality only occurred in twelve out of 31 cases; therefore, it has been suggested that nail abnormality should not be a clinical diagnostic indicator of HS [27]. We could confirm this suggestion because there was no nail abnormality in our case.

There was no consanguinity in the family; therefore, finding a homozygous mutation in the PEX26 gene was unexpected. Given the extremely low allele frequency, it is highly possible that the mutation would be inherited from a common ancestor, identical by descent (IBD), not by coincidental mutation occurred by a mutational hotspot. The parents were checked again for any possible connection in their pedigrees including home town, but there was nothing related. The mutation could be a rare polymorphism in a Korean population.

In conclusion, we identified a homozygous PEX26 mutation in a non-consanguineous Korean family with HS. This finding not only expands the mutational spectrum of PEX26 mutation in HS but also confirms the suggested diagnostic features of HS. A genotype- 
phenotype relationship with more studies would help us to understand the normal and pathologic disease mechanism including enamel formation.

Author Contributions: Formal analysis, Y.J.K., Y.A. and J.-W.K.; conceptualization and resources, Y.-J.K. and J.-W.K., writing—original draft preparation, Y.F. and J.-W.K.; writing—review and editing, Y.J.K., Y.A., Y.-J.K., Y.F. and J.-W.K. All authors have read and agreed to the published version of the manuscript.

Funding: This research was supported by a National Research Foundation of Korea (NRF) grant funded by the Korea government (MEST) (NRF-2018R1A5A2024418 and NRF-2020R1A2C2100543 to J.-W.K.), and by grants from the Japan government (MEXT), Grants-in-Aid for Scientific Research (nos. JP19K07386 to Y.A., nos. JP26116007, JP15K21743, and JP17H03675 to Y.F.), grants from the Takeda Science Foundation, the Naito Foundation, and the NOVARTIS Foundation (Japan) for the Promotion of Science (to Y.F.).

Institutional Review Board Statement: The study was conducted according to the guidelines of the Declaration of Helsinki, and approved by the Institutional Review Board of the Seoul National University Dental Hospital.

Informed Consent Statement: Informed consent was obtained from all individual participants included in the study.

Data Availability Statement: The data presented in this study are openly available in ClinVar (http:/ / www.ncbi.nlm.nih.gov/ clinvar, accessed on 20 April 2021), Submission ID: SUB9433438.

Acknowledgments: We thank the participants in this study for their cooperation.

Conflicts of Interest: The authors declare no conflict of interest.

\section{References}

1. Witkop, C.J., Jr. Amelogenesis imperfecta, dentinogenesis imperfecta and dentin dysplasia revisited: Problems in classification. J. Oral Pathol. 1988, 17, 547-553. [CrossRef]

2. Prasad, M.K.; Laouina, S.; El Alloussi, M.; Dollfus, H.; Bloch-Zupan, A. Amelogenesis Imperfecta: 1 Family, 2 Phenotypes, and 2 Mutated Genes. J. Dent. Res. 2016, 95, 1457-1463. [CrossRef]

3. Hu, J.C.; Chun, Y.H.; Al Hazzazzi, T.; Simmer, J.P. Enamel formation and amelogenesis imperfecta. Cells Tissues Organs 2007, 186, 78-85. [CrossRef] [PubMed]

4. Heimler, A.; Fox, J.E.; Hershey, J.E.; Crespi, P. Sensorineural hearing loss, enamel hypoplasia, and nail abnormalities in sibs. Am. J. Med. Genet. 1991, 39, 192-195. [CrossRef] [PubMed]

5. Ong, K.R.; Visram, S.; McKaig, S.; Brueton, L.A. Sensorineural deafness, enamel abnormalities and nail abnormalities: A case report of Heimler syndrome in identical twin girls. Eur. J. Med. Genet. 2006, 49, 187-193. [CrossRef] [PubMed]

6. Ratbi, I.; Falkenberg, K.D.; Sommen, M.; Al-Sheqaih, N.; Guaoua, S.; Vandeweyer, G.; Urquhart, J.E.; Chandler, K.E.; Williams, S.G.; Roberts, N.A.; et al. Heimler Syndrome Is Caused by Hypomorphic Mutations in the Peroxisome-Biogenesis Genes PEX1 and PEX6. Am. J. Hum. Genet. 2015, 97, 535-545. [CrossRef] [PubMed]

7. Neuhaus, C.; Eisenberger, T.; Decker, C.; Nagl, S.; Blank, C.; Pfister, M.; Kennerknecht, I.; Müller-Hofstede, C.; Charbel Issa, P.; Heller, R.; et al. Next-generation sequencing reveals the mutational landscape of clinically diagnosed Usher syndrome: Copy number variations, phenocopies, a predominant target for translational read-through, and PEX26 mutated in Heimler syndrome. Mol. Genet. Genom. Med. 2017, 5, 531-552. [CrossRef] [PubMed]

8. Martin, M. Cutadapt removes adapter sequences from high-throughput sequencing reads. EMBnet.J. 2011, 17, 3. [CrossRef]

9. Li, H.; Durbin, R. Fast and accurate long-read alignment with Burrows-Wheeler transform. Bioinformatics 2010, 26, 589-595. [CrossRef]

10. $\mathrm{Li}, \mathrm{H}$. A statistical framework for SNP calling, mutation discovery, association mapping and population genetical parameter estimation from sequencing data. Bioinformatics 2011, 27, 2987-2993. [CrossRef]

11. Van der Auwera, G.A.; Carneiro, M.O.; Hartl, C.; Poplin, R.; Del Angel, G.; Levy-Moonshine, A.; Jordan, T.; Shakir, K.; Roazen, D.; Thibault, J.; et al. From FastQ data to high confidence variant calls: The Genome Analysis Toolkit best practices pipeline. Curr. Protoc. Bioinform. 2013, 43, 11.10.11-11.10.33. [CrossRef]

12. Wang, K.; Li, M.; Hakonarson, H. ANNOVAR: Functional annotation of genetic variants from high-throughput sequencing data. Nucleic Acids Res. 2010, 38, e164. [CrossRef]

13. Shi, Y.; Majewski, J. FishingCNV: A graphical software package for detecting rare copy number variations in exome-sequencing data. Bioinformatics 2013, 29, 1461-1462. [CrossRef]

14. Matsumoto, N.; Tamura, S.; Fujiki, Y. The pathogenic peroxin Pex26p recruits the Pex1p-Pex6p AAA ATPase complexes to peroxisomes. Nat. Cell Biol. 2003, 5, 454-460. [CrossRef] [PubMed] 
15. Tsukamoto, T.; Yokota, S.; Fujiki, Y. Isolation and characterization of Chinese hamster ovary cell mutants defective in assembly of peroxisomes. J. Cell Biol. 1990, 110, 651-660. [CrossRef] [PubMed]

16. Itoh, R.; Fujiki, Y. Functional domains and dynamic assembly of the peroxin Pex14p, the entry site of matrix proteins. J. Biol. Chem. 2006, 281, 10196-10205. [CrossRef]

17. Shimizu, N.; Itoh, R.; Hirono, Y.; Otera, H.; Ghaedi, K.; Tateishi, K.; Tamura, S.; Okumoto, K.; Harano, T.; Mukai, S.; et al. The peroxin Pex14p. cDNA cloning by functional complementation on a Chinese hamster ovary cell mutant, characterization, and functional analysis. J. Biol. Chem. 1999, 274, 12593-12604. [CrossRef]

18. Hosoi, K.I.; Miyata, N.; Mukai, S.; Furuki, S.; Okumoto, K.; Cheng, E.H.; Fujiki, Y. The VDAC2-BAK axis regulates peroxisomal membrane permeability. J. Cell Biol. 2017, 216, 709-722. [CrossRef] [PubMed]

19. Matsumoto, N.; Tamura, S.; Furuki, S.; Miyata, N.; Moser, A.; Shimozawa, N.; Moser, H.W.; Suzuki, Y.; Kondo, N.; Fujiki, Y. Mutations in novel peroxin gene PEX26 that cause peroxisome-biogenesis disorders of complementation group 8 provide a genotype-phenotype correlation. Am. J. Hum. Genet. 2003, 73, 233-246. [CrossRef]

20. Tanaka, A.J.; Okumoto, K.; Tamura, S.; Abe, Y.; Hirsch, Y.; Deng, L.; Ekstein, J.; Chung, W.K.; Fujiki, Y. A newly identified mutation in the PEX26 gene is associated with a milder form of Zellweger spectrum disorder. Cold Spring Harb. Mol. Case Stud. 2019, 5. [CrossRef]

21. Berendse, K.; Engelen, M.; Ferdinandusse, S.; Majoie, C.B.; Waterham, H.R.; Vaz, F.M.; Koelman, J.H.; Barth, P.G.; Wanders, R.J.; Poll-The, B.T. Zellweger spectrum disorders: Clinical manifestations in patients surviving into adulthood. J. Inherit. Metab. Dis. 2016, 39, 93-106. [CrossRef] [PubMed]

22. Daich Varela, M.; Jani, P.; Zein, W.M.; D’Souza, P.; Wolfe, L.; Chisholm, J.; Zalewski, C.; Adams, D.; Warner, B.M.; Huryn, L.A.; et al. The peroxisomal disorder spectrum and Heimler syndrome: Deep phenotyping and review of the literature. Am. J. Med. Genet. C Semin. Med. Genet. 2020, 184, 618-630. [CrossRef]

23. Weller, S.; Cajigas, I.; Morrell, J.; Obie, C.; Steel, G.; Gould, S.J.; Valle, D. Alternative splicing suggests extended function of PEX26 in peroxisome biogenesis. Am. J. Hum. Genet. 2005, 76, 987-1007. [CrossRef]

24. Guder, P.; Lotz-Havla, A.S.; Woidy, M.; Reiß, D.D.; Danecka, M.K.; Schatz, U.A.; Becker, M.; Ensenauer, R.; Pagel, P.; Büttner, L.; et al. Isoform-specific domain organization determines conformation and function of the peroxisomal biogenesis factor PEX26. Biochim. Biophys. Acta Mol. Cell Res. 2019, 1866, 518-531. [CrossRef] [PubMed]

25. Steinberg, S.J.; Dodt, G.; Raymond, G.V.; Braverman, N.E.; Moser, A.B.; Moser, H.W. Peroxisome biogenesis disorders. Biochim. Biophys. Acta 2006, 1763, 1733-1748. [CrossRef] [PubMed]

26. Smith, C.E.; Poulter, J.A.; Levin, A.V.; Capasso, J.E.; Price, S.; Ben-Yosef, T.; Sharony, R.; Newman, W.G.; Shore, R.C.; Brookes, S.J.; et al. Spectrum of PEX1 and PEX6 variants in Heimler syndrome. Eur. J. Hum. Genet. 2016, 24, 1565-1571. [CrossRef] [PubMed]

27. Gao, F.J.; Hu, F.Y.; Xu, P.; Qi, Y.H.; Li, J.K.; Zhang, Y.J.; Chen, F.; Chang, Q.; Song, F.; Shen, S.M.; et al. Expanding the clinical and genetic spectrum of Heimler syndrome. Orphanet J. Rare Dis. 2019, 14, 290. [CrossRef] 